\title{
Discussion on Experiment Teaching of Power Electronics Based on Project Driving Teaching
}

\author{
Shi Lei * \\ College of Engineering, Bohai University, Jinzhou 121000, China \\ email: shileiboda@163.com
}

Keywords: Project Driving Teaching, Power Electronics, Experiment teaching.

\begin{abstract}
Project Driving Experiment Teaching (PDET) was one of the effective ways in implementing "Inquiry Teaching Model", and this paper reformed teaching content and methods of power electronics experiment on the basic of PDET, which was a student-oriented method with a project-based line and needed the teacher act as a guide in order to stimulate the students' interest in learning. In project development, the students understood the knowledge, improved their comprehensive ability and gained professional experience by finding solutions to problems. And the practice proved that such teaching method has achieved very good results.
\end{abstract}

\section{Introduction}

It was particularly important to train the consciousness of innovation and practice ability in teaching process of Power Electronic Technology which was the core curriculum of strong electricity specialty ${ }^{[1]}$, which includes very large content such as the design of rectifiers, the design of inverter, the design of chopper, the design of frequency conversion circuit and power system maintenance etc. However, how to organize experiment teaching effectively in limited classes was the focal points and difficulties in the teaching reform. In view of the practical characteristics of power electronics, the students not only needed to have some experience in circuit debugging, but also needed to have the design and analysis ability as well as the organization and coordination ability in order to undertake development tasks of electric power system.

In traditional experimental teaching, there were much more emphasis on verification of experimental results, and the teachers organized experiment content according to the teaching content in isolation which caused the experiment was boring, the experimental results were similar and could not cultivate students' practical ability effectively ${ }^{[2]}$. In contrast, the teachers organized experiment content according to power project development process by Project Driving Experiment Teaching which was easy to mobilize the students' enthusiasm and initiative to improve their comprehensive ability.

\section{Principle of Project Driving Experiment Teaching}

Project Driving Experiment Teaching is a new experimental teaching method different from traditional mode on the basis of constructivism learning theory, which emphasized that the learning activities must be combined with tasks or problems to drive and maintain students' interest and 
motivation by exploring the solutions to the problems. And PDET was particularly suited for experimental teaching of power electronics because of its course features. Specifically, the fundamental theory, specific method and implementation steps of power electronics would be integrated into a power project which would be divided into several specific tasks as experiment contents $^{[3]}$. Meanwhile, the teachers only play a guiding role of analysis, guidance and comment in the course of experiment. Furthermore, the specific process of Project Driving Experiment Teaching was shown in figure 1.

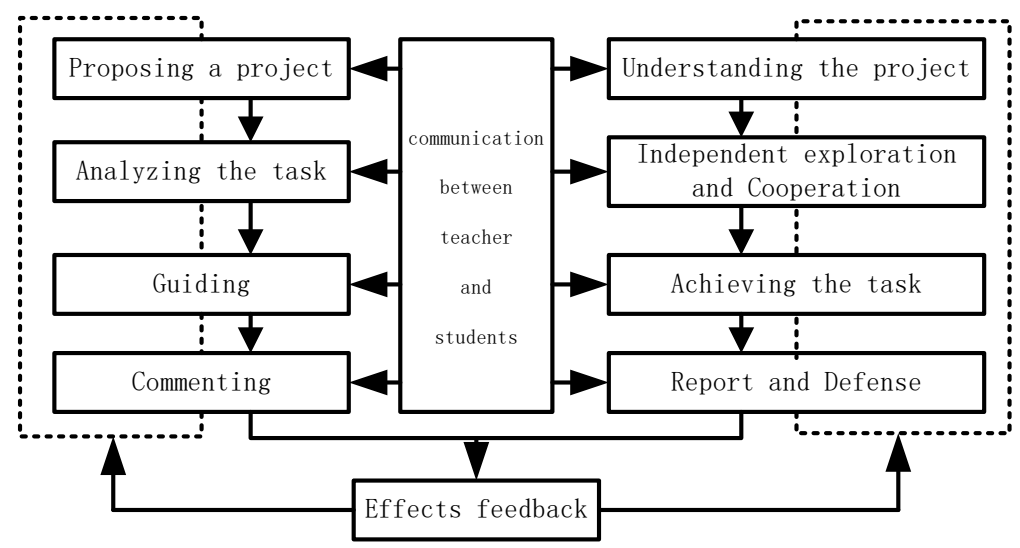

Figure 1 Flow chart of experimental teaching

\section{Features of Project Driving Experiment Teaching}

(1). Authenticity

The power project comes from the actual work and scientific research, meanwhile the results of the project at each stage can be tested according to the actual work.

(2). Comprehensiveness

The power project not only has a complete business process but also contains abundant connotation, which could embody the features of power system at each stage. So the experiment based on project could reflect the teaching content gradually.

(3). Typicality

The power project is composed of a series of specific tasks, and each task could not only reflect theoretical knowledge of power electronics but also contains problems that students may encounter in practice. So the experiment based on project is operational and referential.

(4). Inspire

Different from the traditional experimental model which only focuses on the validation of teaching content, Project Driving Experiment Teaching model is conducted to improve students' ability of discovering problems, analyzing problems and solving problems by asking questions

(5). Openness

Project Driving Experiment Teaching model has the openness of the experimental process, experimental report and evaluation of experimental results, which is quite different from the traditional experimental model ${ }^{[4]}$. And the practice shows that PDET is easy to arouse the enthusiasm of students and initiative and makes the good teaching results.

\section{Organization of Project Driving Experiment Teaching}

\subsection{Selecting the Appropriate Power Project}

The quality of power project could effect on experimental teaching and learning directly, so the 
teacher must select the correct project according to the students' design abilities, system debugging abilities and coordination abilities ${ }^{[5]}$. Firstly, the power project should come from students' familiar fields in order to help them start the project as soon as possible. Secondly, the project should have moderate difficulty and appropriate scale. Finally, the project should have a relatively complete business process and is easy to evaluate. In general, the selected project needs to embody the features of power system at each stage and help to improve the students' abilities of actual hands-on operation.

\subsection{Decomposing the Task Appropriately}

According to cognitive law, Project Driving Experiment Teaching divides the teaching content into several relatively independent and feasible problems to achieve the overall goal by solving these small problems. Furthermore, the basic principles of decomposing task is that the teacher should fully consider the inherent law of power project and students' characteristics in order to assign the tasks best suited to them.

\subsection{Experiment Teaching Process}

In the organization of PDET, it emphasizes the students 'dominant position and the whole experiment teaching process includes 4 parts: grouping, guidance, evaluation and defense.

(1). Grouping

In traditional experimental teaching, each student has the same experimental content. Whereas, Project Driving Experiment Teaching groups the students according to different task content and students ' specialty to clear their different tasks and responsibilities, meanwhile, the teacher selects one with strong comprehensive ability as the group leader.

(2). Guidance

Guidance is one of the basic features of Project Driving Experiment Teaching, especially, dynamicity and openness need asking for the leading function of teachers. Specifically, dynamicity is that the teacher should provide the resources according to the schedule after each group makes its own schedule, and check the progress of the task regularly in order to guide the project development smoothly. However, openness fully reflects the principal part of the students so as to solve the problems met in practice by different forms such as their independent operation, mutual discussion and defense etc. In particular, the teacher should have some practical experience in the power system development in order to guide the development of the project effectively.

(3). Evaluation

The essence of evaluation is that team members coordinate, challenge and discuss throughout the project development ${ }^{[6]}$. So the members cooperate and communicate with each other to find the different sides and solutions of the problem by group evaluation, which could broaden the students' view and improve their comprehensive abilities.

(4). Defense

Finally, the students complete the project report according to the experimental specification of power electronics and make a public defense after the project completion. And the defense is an open process that team members needed to explain their project implementation process, show their designs and innovations and accept challenges for all teachers and students. Meanwhile, each team selects one student as judge with the teacher to mark each project as the final experimental result. In sum, it's easier to develop students' initiative by this way.

\section{Conclusion}

In comparison with traditional experimental teaching methods, there are obvious differences in terms of authenticity, comprehensiveness, typicality, inspire and openness in Project Driving 
Experiment Teaching, which is a teacher-guided and student-oriented model focusing on practice with the project-based line. With the development of power project, the teacher combines theoretical knowledge and methods of power electronics and specific project together and the whole experiment teaching process divided into 4 parts: grouping, guidance, evaluation and defense. Furthermore, the teachers organized experiment content according to power project development process by Project Driving Experiment Teaching which was easy to mobilize the students' enthusiasm and initiative to improve their comprehensive ability.

\section{Acknowledgement}

In this paper, the research was sponsored by the Research Fund for the Doctoral Program of Bohai University (Project No. 0515bs).

\section{References}

[1] Z.H.Qin,C.Deng. The practice and exploration of full English/bilingual teaching for Industrial Engineering majors. International Conference on Information Engineering and Education Science [C]. 2014.

[2] WANG Hua-ji.Practice and Exploration of the Dual-track Project Teaching Method in University Teaching. ICETMS [C]. 2013.

[3] Chunfang Wang,Limin Wang,Aidong Qian.Teaching Practice and Exploration of Animal Anatomy in Higher Agricultural University. 2nd International Conference on Communication Technology[C]. 2015.

[4] Liu Hong fu,Liang Shaohua. Practice and exploration of educational innovation in the teaching process of anatomy [J].Chongqing Medicine, 2012(25) 45-48.

[5] Huansong Yang. The Practice and Exploration of Using Blog in Chinese Writing Teaching of Junior Middle School. 2013 International Conference on Education and Teaching[C]. 2013.

[6] Jiangfeng Li. Exploration of Teaching Practice On College Computer Basic Course Based on the Training of Information Literacy. The 2nd National Conference on Information Technology and Computer Science[C]. 2015. 